\title{
A "obra" da ideologia e a invenção democrática no pensamento de Claude Lefort
}

The "Work" of Ideology and the Democratic Invention in the Thought of Claude Lefort

Renata S. Schevisbiski

Universidade Estadual de Londrina | Paraná | Brasil

\section{RESUMO}

Uma questão pouco discutida nas interpretações sobre o pensamento de Claude Lefort relativas à invenção democrática diz respeito à "obra” da ideologia na democracia, a qual nos remete ao problema da criação histórica e da busca constante pela anulação do sentido político inerente a esta forma de sociedade, calcada na incerteza, na indeterminação e no conflito como fontes de liberdade política. Este trabalho discute o significado da ideologia como um discurso que visa aplacar e desvitalizar o caráter inventivo da democracia. Para tanto, apresentamos ao leitor a compreensão lefortiana de democracia, entendida no seu caráter ambíguo, uma vez que está sujeita tanto à invenção como à cristalização ideológica, estando, por sua vez, na dependência de um trabalho permanente de interrogação das ideologias por parte do homem democrático.

\section{PALAVRAS-CHAVE}

Lefort; Democracia; Ideologia.

\begin{abstract}
A matter that is under theorized in the interpretations of the thinking of Claude Lefort relative to the invention of democracy, concerns the "work" of ideology in democracy, which takes us to the problem of the historic creation and the constant search for the annulment of the public sense inherent to this form of society, based on uncertainty, on indetermination, and on conflicts as sources of political liberty. This work discusses the meaning of ideology as a discourse that aims to appease and devitalize the inventive character of democracy. To do so, we present to the reader the Lefortian comprehension of democracy, understood in its ambiguous character, once it is subject to both the invention, as it is to ideological crystallization, being, in turn, on the dependence of a permanent work of interrogation of ideologies by the democratic men.
\end{abstract}

\section{KEY WORDS}

Lefort; Democracy; Ideology. 
Os escritos de Claude Lefort trazem a marca de uma interrogação sobre a democracia. Após sua saída do grupo Socialisme ou Barbarie em I958, no qual foi fundador e atuou juntamente com Cornelius Castoriadis, lança um novo caminho de reflexão que busca pensar a democracia não como um conjunto de instituiçóes, mas como uma forma de sociedade. Na sua perspectiva, a democracia é aquela que acolhe e preserva a indeterminação, a incerteza e que reconhece a divisão e a diferenciação social como fontes de legitimidade política. A democracia é sinônimo de invenção e de revolução permanentes, pois não há apenas conservação de direitos, mas uma dinâmica ininterrupta de criação de novos direitos. Nesse sentido, ela é a sociedade histórica por excelência, sempre aberta ao novo, aos acontecimentos, fundada em uma ética da dúvida. O problema a ser discutido, no entanto, diz respeito ao papel da ideologia na democracia, pois constitui um discurso que trabalha em favor de um desejo de conservação e tem por finalidade produzir fundamentos que estão sempre em falta naquele regime, a fim de interromper o trabalho da interrogação que nasce com a incerteza característica da sociedade democrática. A ideologia procura criar determinaçōes, "fórmulas" prontas a serem aplicadas, sempre seguindo a linha dos novos questionamentos que surgem na democracia, criando uma representação e uma imagem da divisão social. Torna-se fundamental, então, discutir os efeitos da indissociabilidade entre determinação e indeterminação, entre certeza e incerteza que Lefort nos leva a pensar sob o ponto de vista da "obra" da ideologia na democracia. Para tanto, abordarei inicialmente de que modo Lefort compreende a ideologia para, em seguida, apresentar algumas consideraçóes sobre o papel da ideologia na democracia.

\section{A ideologia como "obra"}

Nas reflexões de Lefort sobre a ideologia, não se trata de permanecer em uma discussão conceitual, abstrata, mas de pensar a sua gênese, isto é, buscar compreendê-la como um discurso que é inerente às sociedades históricas, sendo engendrado em cada época, isto é, em cada aqui e agora e que, por sua vez, não se desprende do trabalho de pensamento que se dá na sociedade moderna. Lefort desvia das definiçôes estabelecidas; não procura discutir o conceito de ideologia, nem busca apresentar o seu próprio; o que não quer dizer que ignore o que se pensa sobre ela em sua época, pois marca um modo de pensar que entende chegar a ela por outra via: pela ideia de que a ideologia nasce e renasce de maneira permanente, $o$ que torna fundamental explicitar as condiçóes que possibilitam o seu surgimento por meio de uma compreensão da forma de sociedade que a produz, a saber, a sociedade moderna que tem a qualidade de ser histórica.

É importante explicitar que no pensamento de Lefort, a expressão "forma de sociedade" não coincide com a perspectiva sociológica e marxista, as quais tomam 
o social como sendo da ordem do fato, que pode ser objetivamente analisado em suas partes, ou ainda, como um conjunto de relações determinadas pela esfera econômica. Para Lefort, o social não é da ordem do fato, coisa em si oferecida ao entendimento, mas é Ser social (Lefort, 1978, p. I5), que não coincide consigo mesmo, no espaço e no tempo, estando implicado no eterno questionamento de si. ${ }^{\mathrm{I}}$ Nessa perspectiva, qualquer agrupamento humano, em cada época, encontra-se às voltas com uma questão origem que não pode ser possuída, nem está em pleno alcance dos sujeitos sociais, mas comanda secretamente as articulações de uma sociedade. Podemos dizer que esta questão é de ordem metassociológica (cf. Lefort, 1974, p. 308), pois ela é instituinte e, portanto, conduz, de maneira não aparente, um jogo de respostas que vem a constituir uma forma de sociedade, o conjunto de suas articulaçōes e relações internas e com seu fora, isto porque o social é pensado em termos de seu limite, na relação que mantém consigo mesmo e com o que o ultrapassa. ${ }^{2}$

Assim, toda sociedade está atrelada a uma questão-enigma ou, como denomina Lefort, ao "enigma da instituição" (Lefort, 1987, p. 324; 1974, p. 314) que guarda em si a ideia de uma origem, de um nascimento da sociedade, mas que não pode ser localizado em um ponto pré-social, fora do próprio tempo e de seu espaço. A singularidade deste enigma está na compreensão do deciframento, no trabalho do pensamento e da ação realizados pelos sujeitos sociais, de modo que o social pode ser entendido como obra ou, ainda, como "instituição" na acepção do verbo "instituir".

I Para compreendermos esta não-coincidência, é importante nos remetermos brevemente a Merleau-Ponty, o qual pensou o Ser como não idêntico a si mesmo. Segundo esta visão, o Ser é reversibilidade, pois não pode ser entendido como estando fora - no mundo externo, na linha do empirismo - , nem dentro, de acordo com o intelectualismo que compreende o Ser como recepção passiva dos estímulos que vêm do "real". Ao mesmo tempo, o Ser também não é síntese do interior e do exterior como é possível compreender por meio da noção de corpo, pois o tocar e ser tocado faz parte de uma só experiência, na qual não é possível determinar quem toca e quem é tocado. Nesse sentido, segundo Bernard Flynn (1984), Merleau-Ponty faz uma crítica ao empirismo e ao intelectualismo, pois estão calcados na separação sujeito-objeto, uma vez que tem em vista a descoberta do corpo reflexivo e do conceito de carne como "arquétipos do Ser" (Flynn, 1984, p. I3). Há, portanto, divergência, não coincidência do Ser consigo mesmo e com o fora, um movimento de ir e vir nestas dimensões, abrindo caminho para a ideia de que ele é indeterminação, Ser não positivo, pois tem dobras, lacunas. Sobre essa compreensão do Ser encarnado, segundo Merleau-Ponty, conferir A estrutura do Comportamento (2006a) e Fenomenologia da percepção (2006b).

2 Para Lefort, o social é compreendido como "espaço social", pois ele se mantém como questão sobre seu limite ou seu "fora” (cf. Lefort, I974, p. 3II). Isso significa que toda sociedade pode ser compreendida como uma resposta dada a esta questão, contribuindo para engendrar diferentes tipos de sociedade, como é o caso da sociedade moderna, referida a seu espaço interno e não mais ao "fora", a outro lugar, representado na figura de Deus, deuses que caracterizam as sociedades regidas pela religião e pelo mito. 
A instituição do social, portanto, remete-nos a um conjunto de significações constituídas pelos homens a fim de darem sentido às suas açôes, às suas condutas, sendo algo que não se desprende do trabalho do pensamento e da ação que se defronta sempre com a mesma questão-origem. Assim, afirma Lefort, trata-se de uma elaboração que atesta toda sociedade política, realizada pelos sujeitos que procuram decifrá-la, contendo "uma interrogação sobre o mundo e sobre o Ser como tal" (Lefort, I98I, p. 255). Nessa perspectiva, as respostas produzidas pelos homens, em cada época, podem ser entendidas como um deciframento da questão-enigma remetida como está à diferenciação, isto é, à divisão social. ${ }^{3}$ Essas respostas podem se dar, por um lado, na forma de um discurso instituinte da ordem social que se remete ao fora, isto é, a uma potência exterior ao social, como é o caso do discurso mítico, religioso que cria um fundamento para a sociedade, remetendo-a a deuses, a Deus, e não podendo ser colocado em questão, definindo um gênero de historicidade que a mantém petrificada; por outro lado, o discurso instituinte também pode permanecer como discurso interrogativo, isto é, desdobrar-se em múltiplos questionamentos que, na tentativa de decifrar o significado da ordem social, são capazes de manter a questão-origem aberta, este é o caso da sociedade histórica. Nesta sociedade ainda, o discurso instituinte pode dobrar-se em um discurso da certeza, necessariamente determinista, fechado, afirmando-se como tese sobre a ordem social. Este discurso fechado, que segue as linhas do discurso instituinte em seu formato interrogativo, conforme veremos mais à frente, é a ideologia.

Sabendo que cada forma de sociedade elabora uma resposta para a questão-origem, vejamos, por exemplo, o caso das sociedades regidas pelo mito e pela religião, denominadas por Lefort como "sociedades não-histórias" (Lefort e Gauchet, I97I, p. 24). Nelas, a resposta dada é constantemente reenviada a um polo externo — a deuses, a Deus — de tal forma que o arranjo social se dá como um "invisível materializado", ou seja, as relaçôes sociais como um todo são vistas a partir de um lugar "fora" do espaço social, o qual materializa aquilo que não pode ser visto, questionado, pelos homens, mas que rege a sua vida social. A resposta, portanto, constitui a organização da sociedade que é feita de uma afirmação que não pode ser contestada, pois está alicerçada em crenças e costumes e é comandada pela tradição. Dessa maneira, a sociedade apreende-se pela formulação de uma certeza mítica, religiosa, sobre o significado do social. O discurso instituinte, portanto,

3 Isso significa que cada sociedade pode ser compreendida como um encadeamento de respostas, como afirma Lefort na interpretação da obra de Maquiavel (cf. Lefort, I986b, p. 513), cujas expressões são individuais e coletivas. Essas respostas constituem sempre possíveis, pois podem ou não obliterar o desejo de liberdade. Temos, então, a ditadura ou a democracia como formas de sociedade que se compreendem por este jogo de possíveis, significando que nem uma nem outra podem ser vistas como formas puras, estanques, distanciadas, mas que contêm em si mesmas a possibilidade latente de sua reversão. 
desdobra-se em um discurso mítico, religioso ${ }^{4}$ que não pode ser questionado, justamente porque o discurso nutre-se de uma potência externa, invisível.

Nas sociedades onde se operou uma quebra com esta ordem transcendente — a sociedade moderna ou sociedade histórica, segundo Lefort —, a questão-origem é respondida segundo outra interpretação, pois as respostas não reenviam a um polo exterior, mas ao próprio espaço social. Dessa maneira, seu discurso instituinte torna-se um discurso interrogativo, ou seja, ele incorpora e mantém a questão-origem, fazendo com que a sociedade histórica se constitua como sociedade da interrogação. A despeito das respostas formuladas pelos homens, em cada tempo histórico, há um constante reenvio à questão-enigma, particularmente por intermédio dos acontecimentos que são potência de desordem e criam possíveis. Nasce, então, a possibilidade de um discurso interrogativo, aberto, em que a temporalidade e a divisão social podem ser colocadas constantemente em questão.

Ao pensarmos estas duas formas de sociedade, estamos lidando, então, com dois imaginários, pelos quais a ordem social pode manter-se petrificada ou não. Mas, neste último caso, o da sociedade histórica, há uma complicação a mais, pois há a tentativa constante de manter oculta a questão-origem. Toda vez que se procura "colocar o pensamento em contato com o instituinte" (Lefort, 1974, p. 314), através de lutas sociais, do trabalho da contestação no bojo dos acontecimentos, surge um "discurso do ocultamento" (Ibid., p. 309), isto é, uma nova ideologia. Nesse sentido, o imaginário da sociedade histórica mantém uma especificidade importante: um parentesco com o imaginário da sociedade sem história, por meio da ideologia. A ideologia, então, se constitui como o "encadeamento das representações que têm por função restabelecer a dimensão da sociedade 'sem história' no seio da sociedade histórica." (Ibid., p. 313).

Assim, se algumas sociedades se abrem para a história e outras se fecham, o mais enigmático, sem dúvida, é que nas sociedades históricas há, cito Lefort: "os sinais sempre persistentes de uma resistência à mudança, de uma tendência sempre reiterada a um fechamento nos limites já conquistados" (Lefort, I987, p. 306). Portanto, Lefort busca discutir a ideologia como discurso nascido na sociedade histórica, a fim de compreender o significado da denegação da história, do acontecimento produzido por ela. O que a ideologia faz, nesse sentido, é interditar o reenvio constante ao enigma da instituição que permite aos homens pensarem e repensarem suas próprias práticas e representações e criarem possiveis.

A ideologia, portanto, no pensamento de Lefort, pode ser entendida como um discurso segundo, pois "segue as linhas do discurso instituinte" (Lefort, 1974,

4 Ainda que haja diferenças entre esses discursos, no pensamento de Lefort eles conservam um traço comum: são compreendidos como discursos que criam a representação de uma comunidade imaginária que permanece reportada ao fora e não ao social. 
p. 315), ou seja, ela nasce como desdobramento de um discurso primeiro que contém em si mesmo todos os signos da criatividade histórica, de um questionamento nascido no âmago da divisão social, entendida como brecha, como fenda na sociedade. Isso quer dizer que ela não se dissocia do jogo político, das relações de embate entre as classes, das lutas sociais que surgem, em cada aqui e agora, no espaço social histórico.'

A ideologia, enquanto "dobra" do discurso instituinte, nasce e se mantém presa a ele, reconhecendo-o e denegando-o ao mesmo tempo. Ela conhece e reconhece muito bem as propriedades da sociedade histórica, de sua divisão, pois resulta de um trabalho de interpretação dos enunciados abertos, questionadores, criativos, com vistas a anular toda a sua expressividade, a sua descoberta. Ela é, portanto, uma afirmação, uma certeza, uma determinação sobre o significado da sociedade, das relaçôes sociais, do poder, pois procura, cito Lefort, "desarmar as oposições e rupturas no duplo registro do espaço e do tempo" (Lefort, 1974, p. 313). A ideologia está na dependência do discurso instituinte; dissimula o histórico pela fantasmagoria do "novo", do "moderno", ou seja, cria a ilusão para mascarar a diferença temporal. Ela também realiza o projeto de homogeneização social, criando respostas para as questôes surgidas com a divisão social, inscrita nos conflitos de classe, étnicos e assim por diante. O que a ideologia faz é neutralizar a história, dissimular a irrupção da diferença e desarmar a interrogação (Lefort, 1976, p. 28I). A ideologia, portanto, é "obra de ocultamento" (Lefort, I974, p. 313) da divisão e da história, pois toda vez que há mudanças nas mentalidades, nos comportamentos coletivos ou, ainda, quando núcleos de potência se deslocam nas relações de poder entre as classes, por exemplo, ela rearranja seus próprios enunciados para dar conta do recobrimento, para que seus enunciados

5 Thompson (1982) comenta esta perspectiva de Lefort que pensa a ideologia como "dobra", considerando um problema: como é possível distinguir entre discurso instituinte e discurso instituído, sendo este pensado como discurso da dissimulação, sem que se pressuponha algum critério de "real", a referência segundo a qual o processo de instituição pode ser circunscrito? (cf. Thompson, I982, p. 675). Primeiramente, podemos dizer que Lefort não pensa a ideologia como um discurso que se "distingue" do discurso instituinte, como se houvesse uma separação e no seu meio o real como algo dado, entendido como uma verdade capaz de falsificar a ideologia. Nessa perspectiva, o real não pode ser afirmado frente à ideologia pura e simplesmente, mas depende de um trabalho de pensamento, de crítica das ilusões que se dá também no reenvio ao discurso instituinte. Assim, se ele pode ser pensado por Lefort como aquilo "que denuncia a possibilidade do encobrimento” (Lefort, I974, p. 309) é porque ele está sempre em suspensão, à espera deste trabalho. Se podemos definir algum critério para aquela distinção, pensada por Thompson (I982), este não está no real dado, mas sim neste trabalho de crítica da ideologia e de reenvio ao discurso instituinte, o qual pertence a cada tempo histórico. Como afirma Molina, neste mesmo sentido, não se deve possuir o conceito de real, pois "a verdadeira realidade social não pode ser concebida independentemente da ideologia” (Molina, 2005, p. I59). 
continuem fazendo sentido e conferindo uma correspondência à nova trama das relações. Assim, sempre que novas "fendas" são abertas pelos agentes sociais no trabalho de contestação da ordem estabelecida, isto é, que novos acontecimentos surgem através de um retorno à questão-origem, a ideologia rearticula seus enunciados, seus signos representativos, para entulhar e fechar a "brecha" aberta na sociedade. Seu trabalho, ou melhor, sua "obra", é ocultar a divisão social como engendramento da história.

\section{Ideologia e invenção democrática}

Com isso, chegamos, então, à segunda parte deste artigo, ao ponto central: refletir um pouco sobre o papel da ideologia na democracia, ou, melhor, no trabalho de invenção democrática. Trata-se de pensar os efeitos da obra da ideologia que consiste na tentativa constante de aplacar o caráter inventivo da democracia, transformando o indeterminado em determinado, a incerteza em certeza. Nesse sentido, lidamos com o problema da criação histórica e da busca da anulação de seu sentido político, por meio de um trabalho (ou melhor, da obra) de cristalização realizado pelo discurso ideológico, o qual tira proveito de dois fundamentos importantíssimos para o processo de invenção democrática:

I. Em primeiro lugar: na democracia há o reconhecimento da legitimidade do conflito. Se, por um lado, esse reconhecimento favorece a existência de uma sociedade civil sempre em gestação, em criação constante de si mesma, através, por exemplo, da criação de direitos, por outro, temos a ideologia que consiste na tentativa constante de denegar e anular o caráter instituinte da divisão.

2. Em segundo lugar, tendo em vista que a democracia perfaz uma sociedade que permanece em uma busca constante de sua identidade, fundada em uma interrogação, a ideologia constitui um discurso em forma de resposta, principalmente contra a ameaça de perda de si que habita o social nos regimes democráticos. Ilustrativa dessa perspectiva é a tentativa de sacralização das instituições pelo discurso burguês. De acordo com Lefort, "o culto burguês da ordem, que se sustenta com a afirmação da autoridade em suas múltiplas figuras, com o enunciado das regras e das devidas distâncias entre os que ocupam a posição do senhor, do proprietário, do homem cultivado, do homem civilizado, do homem normal, adulto, face ao outro, todo esse culto testemunha uma vertigem perante a voragem de uma sociedade indefinida" (Lefort, I979a, p. II9).

Nessa linha de reflexão, o mais intrigante nas reflexões de Lefort sobre a ideologia encontra-se na compreensão de que a indeterminação que atravessa a democracia é geradora de uma ambiguidade importantíssima a ser discutida e que ela carrega um significado político. Ao submeter os homens à prova do trágico e da dúvida, uma vez que não há mais um fundamento para a ordem social, 
mas a ideia de uma identidade social sempre sujeita ao trabalho da interrogação e da elaboração de discursos sociais, a ideologia realiza uma "obra", no sentido de fornecer uma resposta pronta e acabada aos questionamentos existentes na democracia. Isso significa, por um lado, que a ideologia cria uma determinação e, com isso, favorece a cristalização democrática e, consequentemente, a sua desvitalização, no sentido de lhe apresentar fundamentos para uma identidade que não correspondem ao seu caráter instituinte; por outro, no pensamento de Lefort, ela nunca conseguirá impedir o trabalho da dúvida na democracia.

Isso significa, então, a possibilidade de pensarmos que a ideologia na democracia é sinal de suas ambiguidades. Para Lefort, a obra da ideologia não consegue pôr um termo à democracia, pois seu trabalho, destinado que está à restituição da certeza, não consegue impedir que nasça a incerteza que anima este regime (cf. Lefort, $1983 \mathrm{~b}, \mathrm{p} .35$ ). Assim, o trabalho da ideologia não coloca um fim ao trabalho da interrogação que anima a democracia; não apaga o trabalho feito pela revolução democrática, isto é, a destruição dos fundamentos de legitimidade e de verdade.

Lefort não prega, portanto, a destruição do discurso ideológico, porque recairia na utopia marxista. Ele considera que a ideologia sempre existirá, sua gênese é permanente e ela continuará seu trabalho sobre a democracia, sua obra - palavra que nos dá a noção de que há certezas partilhadas pelos sujeitos sociais, as quais, no entanto, não chegam a impedir completamente o exercício da dúvida, das interrogaçôes que alimentam a crítica e os reenviam ao discurso instituinte. Nesse sentido, ocorre a fundação constante da política, a invenção permanente da sociedade política, pois, ainda que a ideologia procure determinar o pensamento do homem democrático, Lefort considera que ele é trabalhado pela incerteza e que todo o saber ideológico que possui, permanece vinculado ao não-saber, isto é, aos "possíveis", ao "talvez", que abrem uma carreira para a indeterminação democrática.

Cito Lefort:

Pouco importam todos os meios postos por obra da ideologia dominante a fim de impor os novos critérios de julgamento social; por maior que seja sua eficácia, eles não podem apagar definitivamente o trabalho feito pela revolução democrática, isto é, a destruição dos fundamentos da legitimidade e da verdade. Quando é definido como independente, o indivíduo não troca, como parece supor Tocqueville, uma certeza por outra - a que derivaria no presente de sua autonomia, ou então, inversamente, a que o faria se arrimar ao poder da opinião ou ao poder da ciência. Ele está destinado a continuar sendo em surdina trabalhado pela incerteza. Desde que a verdade não possa se desprender do exercício do pensar, desde que o direito, em virtude do qual o indivíduo é afirmado, mostre-se ligado à sua própria faculdade de enunciá-lo, saber e não-saber se combinam sem que se possa jamais separá-los. E mesmo 
esta distinção entre pensamento e direito não dá conta da novidade do acontecimento, pois o exercício do pensar modifica-se quando é afirmado um direito de pensar, direito indefinido, por certo, mas que leva sempre mais longe o que era outrora afeito ao interdito. Tal direito não se circunscreve aos limites do político; concerne todas as relaçôes que o indivíduo mantém com o mundo, com outros, consigo mesmo, concerne todos os seus pensamentos, funda-os, no mesmo momento em que os faz advir (Lefort, 1982, pp. 213-214, grifo nosso e grifo do autor).

A democracia é uma forma de sociedade que assume uma interrogação interminável, sendo, para Lefort, uma sociedade filosófica ${ }^{6}$, mas, ao mesmo tempo, as questôes que formula estão sujeitas a serem apreendidas pelo discurso ideológico, na medida em que ele procura impedir este trabalho de interrogação, pela elaboração de respostas que têm o efeito de recobrir o profícuo exercício da dúvida, criando determinaçốes para a prática social. É por isso que ela deve manter-se em estado de interrogação permanente, ou ainda, como "democracia selvagem" (Abensour, 2002), procurando sempre escapar à ideologia.

$\mathrm{Na}$ realidade, eu creio que a sociedade democrática, se ela se arrisca a se deteriorar nas divisóes de fatos e de interesses ou a cair num relativismo e num niilismo, é aquela também que é a mais exigente e a mais filosófica, porque é nela que os fundamentos da lei, do poder e das relaçōes sociais, são objeto de um "colocar em questão" contínuo (Lefort, 1986a, p. 563).

Nesse sentido, podemos pensar na relevância de uma ética da dúvida, isto é, de um trabalho constante de interrogação que seja responsável por colocar em contradição o discurso ideológico. A interrogação, a qual se refere Lefort, não se dissocia de uma análise das relações sociais, da divisão social, do discurso que as articula e oculta, isto é, da ideologia (cf. Lefort, 1988, p. 602). Somente dessa forma pode-se impedir que a sociedade democrática se petrifique no discurso ideológico.

Nessa perspectiva, a ideia de interrogação deve ser explicitada, pois ela se diferencia de uma tagarelice sábia. Na democracia, há a liberdade de falar, de dar opiniōes, mas há uma diferença importante a ser pensada: pode haver uma linguagem interrogativa, capaz de colocar a ideologia em contradição, mas também uma "falsa crítica". A grande questão, então, passa a ser o tipo de reflexão, a natureza do discurso interrogativo que deve ser mantido na democracia e que é capaz de colocar a ideologia em contradição.

6 A democracia é uma sociedade filosófica, na perspectiva de Lefort, porque ela se dá como questão, como interrogação interminável sobre seus próprios fundamentos. 
Finalizo dizendo que ao pensar a "obra" da ideologia no trabalho de invenção democrática, Claude Lefort nos coloca em condição de refletirmos sobre a importância do trabalho de interrogação nesta forma de sociedade. A invenção democrática, como revolução ininterrupta, também está na insurgência contra a linguagem dobrada, característica da ideologia. O homem democrático, portanto, tendo em vista que jamais poderá se separar completamente do discurso ideológico e, estando implicado neste discurso, precisa tornar-se intérprete de seu próprio tempo, através de um trabalho de interrogação, de interpretação e de contestação, em relação à ideologia, a fim de permanecer em contato com o discurso instituinte. Dessa maneira, a crítica não pode ser compreendida como um discurso que se contrapõe ao discurso ideológico pela afirmação de uma tese oposta, como discurso categórico, mas como aquele que desconstrói os enunciados, as representações, que lança mão de ironias, que modifica, desloca ou arruína as significações estabelecidas para fazer emergir aquilo que estava recoberto, para revelar as contradições da ideologia, pois se mantém no modo interrogativo, pelo fato de que restabelece o laço com a questão-origem que ela oculta.

É preciso dizer, por fim, que os sinais que marcam a invenção democrática encontram-se sempre na dependência deste trabalho de interrogação e de interpretação dos discursos que visam criar uma determinação na democracia.

\section{Referências}

Abensour, Miguel (2002). "'Savage democracy' and 'principle of anarchy', Philosophy \& Social Criticism, v. 28, n. 6, London, pp. 703-726.

FuynN, Bernard (1984). "The question of an ontology of the political: Arendt, Merleau-Ponty, Lefort", International Studies in Philosophy, v. xvI, n. I, pp. OI-24.

Lefort, Claude; Gauchet, Marcel (1971). "Sur la démocratie : le politique et l'institution du social", Textures, n. 2-3, pp. 7-78.

Lefort, Claude (1974). "Esboço de uma gênese da ideologia nas sociedades modernas", In Claude Lefort, As formas da história: ensaios de antropologia politica, São Paulo: Brasiliense, 1979b.

Lefort, Claude (1976). "Maintenant", In Claude Lefort, Le temps présent. Écrits 1945-2005, Paris: Éditions Belin, 2007.

Lefort, Claude (1978). "Prefácio", In Claude Lefort, As formas da história: ensaios de antropologia politica, São Paulo: Brasiliense, 1979b.

Lefort, Claude (1979a). "A imagem do corpo e o totalitarismo", In Claude Lefort, A invenção democrática: os limites da dominação totalitária, São Paulo: Brasiliense, i983a.

Lefort, Claude (1979b). As formas da história: ensaios de antropologia política, São Paulo: Brasiliense. 
Lefort, Claude (198I). "Permanência do teológico-político?" In Claude Lefort, Pensando o político: ensaios sobre democracia, revolução e liberdade, trad. Eliana de Melo Souza, Rio de Janeiro: Paz e Terra, I99I.

LEForT, Claude (1982). "Reversibilidade: liberdade política e liberdade do indivíduo", In Claude Lefort, Pensando o político: ensaios sobre democracia, revolução e liberdade, trad. Eliana de Melo Souza, Rio de Janeiro: Paz e Terra, I99I.

Lefort, Claude (1983a). A invenção democrática: os limites da dominação totalitária, São Paulo: Brasiliense.

Lefort, Claude (1983b). "A questão da democracia", In Claude Lefort, Pensando o político: ensaios sobre democracia, revolução e liberdade, trad. Eliana de Melo Souza, Rio de Janeiro: Paz e Terra, I99I.

Lefort, Claude (1986a). "La dissolution des repères et l'enjeu démocratique", In Claude Lefort, Le temps présent. Écrits 1945-2005. Paris: Belin, 2007.

Lefort, Claude (1986b). Le travail de l'œuvre Machiavel, $2^{\mathrm{ème}}$ ed., Paris: Gallimard.

Lefort, Claude (1987). "Dialogando com Pierre Clastres", In Claude Lefort, Desafios da escrita política, trad. Eliana de Melo Souza, São Paulo: Discurso Editorial, 1999.

Lefort, Claude (1988), "La pensée du politique”, In Claude Lefort, Le temps présent. Écrits 1945-2005, Paris: Belin, 2007.

Lefort, Claude (199I). Pensando o político: ensaios sobre democracia, revolução e liberdade, trad. Eliana de Melo Souza, Rio de Janeiro: Paz e Terra.

Lefort, Claude (1999). Desafios da escrita politica, trad. Eliana de Melo Souza, São Paulo: Discurso Editorial.

Lefort, Claude (2007). Le temps présent. Écrits 1945-2005, Paris: Éditions Belin.

Merleau-Ponty, Maurice (2006a). A estrutura do comportamento, São Paulo: Martins Fontes.

Merleau-Ponty, Maurice (2006b). Fenomenologia da percepção, São Paulo: Martins Fontes.

Molina, Esteban (2005). Le défi du politique. Totalitarisme et démocratie chez Claude Lefort, Paris: L'Harmattan.

Thompson, John B. (1982). "Ideology and the social imaginary. An appraisal of Castoriadis and Lefort", Theory and Society, v. II, n. 5, pp. 659-68I. 